\title{
Conductive Argument as a Mode of Strategic Maneuvering
}

\author{
YUN XIE \\ Institute of Logic and Cognition \\ Department of Philosophy \\ Sun Yat-sen University \\ Guangzhou, China \\ xieyun6@mail.sysu.edu.cn
}

\begin{abstract}
This paper argues that conductive arguments may be understood from a rhetorical perspective. It demonstrates that conductive arguments can be regarded as a particular mode of strategic maneuvering, and their uses can be adequately analyzed and evaluated by adopting the theoretical tools developed in extended Pragma-Dialectics. Moreover, it contends that conductive arguments should not be characterized as representing the mechanism of weighing and balancing to reach a conclusion, therefore treating them as a new logical type might be misleading.
\end{abstract}

Résumé: On soutient qu'on peut comprendre les arguments conducteurs d'un point de vue rhétorique. On démontre qu'on peut les considérer comme un mode particulier de manœuvre stratégique et analyser et évaluer adéquatement leurs utilisations en adoptant les outils théoriques développés dans la PragmaDialectique. En outre, on maintient qu'on ne doit pas qualifier les arguments conducteurs de mécanisme de pondération et d'équilibrage employé pour tirer une conclusion. Par conséquent, les interpréter comme si ils étaient un nouveau type d'argument pourrait être trompeur.

Keywords: conductive argument, Pragma-Dialectics, rhetorical perspective, strategic maneuvering

\section{Introduction}

The topic of conductive argument has attracted much attention in recent argumentation studies. Following Wellman (1971) and Govier (1979, 1987), proponents of conduction strive to justify conductive arguments as "an overlooked type of defeasible reasoning" (Blair \& Johnson 2011). They contend that conductive arguments should be treated as a new type of argument because of its special mechanism of justification and particularly complex structure, both of which call for some new theory and methods for analysis and evaluation. However, the notion of conduction also has its dissenters, who believe that conductive 
argument is a misleading model (Wohlrapp 2011), its distinctiveness as an argument type is a myth (Possin 2012), and its notion is simply a misconception, hence the existence of conductive arguments is not possible (Alder 2013). The controversy remains unsettled (Govier 2011, Blair 2013, Xie \& Xiong 2013, Blair 2016), but most of the existing disputes are centered on a logical or epistemological perspective.

This paper offers an alternative point of view regarding the likelihood and importance of conductive arguments. The basic position is that conductive arguments can be analyzed in an adequate way from a rhetorical perspective. More specifically, it attempts to show that, rather than proposing a new argument typology and searching for some new theory, we could simply treat conductive arguments as a particular mode of strategic maneuvering. In section 2 , I first provide a brief introduction of the concept of conductive argument, and explain why a rhetorical perspective on conduction is possible. In section 3 , a rhetorical interpretation on conductive arguments is clarified, and also defended with theoretical analysis and empirical results. In sections 4-6, I argue that conductive arguments, when understood rhetorically, can be analyzed and evaluated with the Pragma-dialectical tools pertaining to the notion of strategic maneuvering. Then I deal with two major counterconsiderations to my position in section 7 , and draw some conclusions in section 8 .

\section{The concept of conductive argument}

The concept of conductive argument traces back to Carl Wellman and his Challenge and Response: Justification in Ethics (1971). In that book, a type of argument that is neither deductive nor inductive was proposed. Wellman termed it "conduction" (p. 52), and distinguished three patterns (pp. 55-57). Among them, only the third one has received much attention from argumentation scholars, due to its attractively novel mechanism of justification:

The third pattern of conduction is that form of argument in which some conclusion is drawn from both positive and negative considerations. In this pattern reasons against the conclusion are included as well as reasons for it. For example "in spite of a certain dissonance, that piece of music is beautiful because of its dynamic quality and its final resolution" or "although your lawn needs cutting, you ought to take your son to the movies because 
the picture is ideal for children and will be gone by tomorrow". (Wellman 1971, p. 57.)

This pattern has become the most important form of conduction in later discussions, and in this paper I am concerned with this type. ${ }^{1}$ Indeed, in many occasions when we argue for a view on issues that are controversial, besides providing reasons to support our conclusion, we also try to introduce some reasons that go against it. This common phenomenon is now to be captured by the concept of conductive argument. The beauty of conductive argument, then, lies in the fact that there is no other type of argument that explicitly collects both affirmative and negative reasons bearing on the conclusion into a single structure, and thereby indicates that the conclusion is reached in a way of weighing and balancing. Accordingly, for advocates of conduction, the inclusion of counter-considerations in a conductive argument thus challenges our traditional theories for argument analysis and evaluation: it reveals our ignorance of a longstanding way of arguing (prevailing in some special contexts); it enriches our understanding of non-deductive support; it challenges our former definitions of 'reason' and 'premise'; and it calls for new theory to pin down its argument structure and to unpack its mechanism of weighing. Meanwhile, the recognition of conduction as a new argument type would also broaden the scope of our argumentation studies (see Blair 2011).

In spite of a sympathy for these theoretical ambitions, I believe some doubt could still be raised on the concept of conduction per se that is primarily related to the possible role of counter-considerations in our acts of arguing. Many proponents of conductive arguments have simply presumed that the presence of counter-considerations needs to be interpreted from a logical perspective: they are provided as (part of) the reasons or premises, or they have played a substantial role in justifying the conclusion. In this connection, they believe that the presence of counter-considerations indicates a need to formulate some implicit "on-balance premise", and therefore adds some complication into the argument structure. However, I suspect that there is an inferential leap taken from the argumentative practices to our argumentation theory: even though we do offer some counter-

\footnotetext{
${ }^{1}$ I take this third pattern as the representative form of conductive arguments, because almost all the discussions of conduction in recent years have focused on this type. However, for those who recognize special theoretical importance of Wellman's first and second patterns of conduction, please feel free to narrow the scope of this paper down to a study merely on Wellman's pattern- 3 conduction, or pro and con arguments.
}

(C) Yun Xie. Informal Logic, Vol. 37, No. 1 (2017), pp. 2-22. 
considerations in arguing, it is not clear that we are doing so exactly for logical concerns. In other words, the mention of a counter-consideration doesn't necessarily mean that the arguer accepts it as a point relevant to the establishment of the conclusion. And yet there still seems to be a lack of evidence or argument for us to safely assume this connection. Therefore, it could also be possible to interpret the presence of counterconsiderations from a perspective other than logical.

\section{A rhetorical perspective on conduction}

Why do we care to present some counter-consideration that has the potential to undermine our claim to be argued for? In reality, the inclusion of counter-considerations in a conductive argument is often realized by the use of an 'even though', 'although', or 'notwithstanding' clause. Hence, the answer to that question could probably be enlightened by examining the pragmatics of those linguistic indicators. It goes without saying that the uses of those even-though type clauses are definitely parts of the speaker's communicative intent, trying to convey something more than that "the conclusion is established by reasons supporting it". From a Gricean point of view, they could serve to convey the conventional implications that "these reasons against the conclusion are outweighed", or that "the speaker has taken account of not just favorable considerations, but unfavorable ones as well" (Adler 2013, p. 247). Moreover, when these conventional implications are indeed recognized by the hearer, it could also have some practical effects on the speaker's argument. Specifically, by implying that the reasons against the conclusion are outweighed, the argument advanced would appear to be more persuasive, and by indicating that both favorable and unfavorable considerations are taken into account, the conclusion to be reached would appear to be more solid. Actually, this speculation has already been verified, to some extent, by research evidence in the field of communication studies. It was reported by the works on message sidedness that the inclusion of counterconsiderations boosts the communicator's credibility and thereby enhance the message's effectiveness, though in complicated ways within different contexts (see O'Keefe 1999).

However, it is worth noting that neither the conveying of these conventional implications, nor the achieving of those practical effects, would necessarily require the arguer to take counter-considerations as reasons or premises pertaining to the establishment of her conclusion. Alternatively, it is possible to inter- 
pret the arguer's communicative intention as to strengthen her argument in a way that does not enhance its justificatory power, but increases its persuasive effect, i.e., makes the argument more likely to induce the adherence of the audience. I would like to call this interpretation a rhetorical perspective on conduction, simply because it regards the mention of counter-considerations as some effort aiming for rhetorical concerns to achieve better persuasiveness. In fact, this rhetorical interpretation on conduction has its origin in the analysis of 'although' and 'even though' expressions made by logicians and linguists. Hansen (2011, pp. 42-48) once provided a brief review of former views about the "even-though relation", where we could find that a logician like Quine has believed that "consideration of 'but' and 'although' ... brings out a distinction between what may be called the logical and the rhetorical aspects of language" (p. 43). There, Hansen also discussed Ducrot's pragmatic analysis and concluded that the use of 'even though', as a conjunction, has its rhetorical roles (p. 47).

Taking this rhetorical interpretation on conduction as the theoretical hypothesis, a pilot empirical study has been conducted, in order to confirm the plausibility of the above analysis. The study was designed from the perspective of the recipient of argument, to investigate what is the possible role of counterconsiderations recognized by the addressee of the argument, and whether the inclusion of counter-considerations does achieve better persuasiveness.

A total of 401 subjects (ranging in age from 18 to 20 , $66.5 \%$ female, $33.5 \%$ male) were asked to compare a pair of arguments, in which the first one consists of a claim supported by two reasons that count for it, while the second is made from the first argument by using an "even though" clause to add two more considerations that count against the claim. The subjects were college students from different majors, but all of them were taking an introductory course on logic when the study was conducted. The course guaranteed that most subjects were prepared with the basic background knowledge relative to argument analysis and evaluation that is necessary to understand the questions and to make appropriate judgments. Nevertheless, the idea of "a reason or premise being (only) the consideration supportive to conclusion" was deliberately suppressed in teaching. All subjects were asked to give their judgment on whether the second argument is more persuasive than the first one, and then to explain why. They were also asked to report whether they recognized the counter-considerations provided by the "even 
though" clause as possible reasons or premises in the argument, and then to explain why.

It turns out that mentioning counter-considerations does achieve an effect of enhanced persuasiveness, for there were 324 subjects $(80.7 \%)$ confirming that the second argument is more persuasive. However, only 43 subjects $(10.7 \%)$ had recognized counter-considerations as reasons or premises. When explaining their judgments, several different accounts with regard to the role of counter-considerations were most often reported. First, a great many of the subjects $(N=159)$ had reported that the inclusion of counter-considerations just made the argument appear to be more comprehensive (well-considered), or more objective (neutral, less biased), because the arguer seems to be aware of information on both sides of the issue, and has taken all of them into consideration. Second, there were still many others $(N=76)$ maintaining that counter-considerations are deliberately mentioned in order to serve as a foil stressing the significance of the positive reasons, and thereby to induce the audience's judgment with a striking contrast. Particularly, it was reported that the arguer was employing a rhetorical figure, namely, a presentational strategy of "repressing before developing", or "retreating in order to advance".

Third, there were some others $(N=51)$ reporting that the arguer's mentioning of counter-considerations is an effort to make the argument appear to be more friendly to the audience. According to them, presenting some counterconsiderations could avoid in advance possible confrontations (or aversions) from the audience, because in doing so the arguer tones down the expression of her argument, and kindly makes concessions to the audience. Fourth, there were still some others $(N=35)$ suggesting that counterconsiderations are offered with the intention to provide some background (or complementary) information, in order to enable the audience to better understand the position argued. ${ }^{2}$

The empirical findings seem to be suggestive, at least for the rhetorical perspective on conduction formulated above. It is reported that the mention of counter-considerations is more likely to be regarded as some effort to give the argument a better appearance, or, to adapt to the audience for establishing communion and gaining adherence. Hence the possible roles of

\footnotetext{
2 It is worth mentioning that there were also subjects $(N=54)$ who reported that presenting counter-considerations in the argument had actually undermined its persuasiveness.
}

(C) Yun Xie. Informal Logic, Vol. 37, No. 1 (2017), pp. 2-22. 
counter-considerations that were recognized by the recipient of conductive arguments are hardly logical, but could be in many ways understood as rhetorical.

Table 1 A summary of the empirical study

\begin{tabular}{|c|c|c|}
\hline & Confirmed & Disconfirmed \\
\hline Enhanced Persuasiveness & $324(80.7 \%)$ & $77(19.3 \%)$ \\
\hline & Recognized & Not-recognized \\
\hline $\begin{array}{l}\text { Counter-considerations as } \\
\text { reasons or premises }\end{array}$ & $43(10.7 \%)$ & $358(89.3 \%)$ \\
\hline
\end{tabular}

Roles of counter-considerations other than reasons and premises

\begin{tabular}{l|c}
\hline $\begin{array}{l}\text { Making the argument appear to be } \\
\text { more comprehensive, more objec- } \\
\text { tive (less biased) }\end{array}$ & $159(39.6 \%)$ \\
\hline $\begin{array}{l}\text { Serving as a foil stressing the signif- } \\
\text { icance of the positive reasons (par- } \\
\text { ticularly, employing a rhetorical, } \\
\text { presentational strategy) }\end{array}$ & $76(18.9 \%)$ \\
\hline $\begin{array}{l}\text { Making the argument appear to be } \\
\text { more friendly (by avoiding possible } \\
\text { confrontations or aversions from the } \\
\text { audience) }\end{array}$ & \\
\hline $\begin{array}{l}\text { Providing background or comple- } \\
\text { mentary information for the audi- } \\
\text { ence }\end{array}$ & \\
\hline
\end{tabular}

\section{Conductive argument and strategic maneuvering}

Taking a rhetorical perspective on conduction, the persuasiveness of conductive arguments can be explained in such a way that the supportive reasons are offered to justify the conclusion, while the counter-considerations are (recognized to be) provided in order to better achieve effectiveness in persuading the audience. In other words, in a conductive argument, the pursuits of two relatively different aims are delicately accomplished at the same time in one argumentative move. This understanding, then, could easily bring to mind a parallel between conductive argu-

(C) Yun Xie. Informal Logic, Vol. 37, No. 1 (2017), pp. 2-22. 
ment and the Pragma-dialectical notion of strategic maneuvering.

Over the last decade, van Eemeren and his colleagues have developed the standard Pragma-dialectical theory of argumentation into an extended version, in which a notion of strategic maneuvering was put forward as the primary theoretical tool (van Eemeren \& Houtlosser 2002; van Eemeren 2010). Basically, it is an attempt to explore more comprehensive analytic and evaluative tools to account for the phenomenon of strategic design in real-life argumentative practice. According to Pragma-dialectics, "people engaged in argumentative discourse are characteristically oriented toward resolving a difference of opinion... [by] maintaining certain critical standards of reasonableness.... At the same time, however, these people are also, and perhaps even primarily, interested in resolving the difference of opinion effectively in favor of their case" (van Eemeren 2010, p. 39). But there is an inherent tension in their pursuing these two objectives simultaneously, because these two endeavors, in many cases, will not go together. Accordingly, in making an argumentative move, an arguer will have to maneuver strategically to reconcile her pursuit of effectiveness with the maintenance of reasonableness.

The notion of strategic maneuvering is therefore designed to capture those "continual efforts made in all moves that are carried out in argumentative discourse to keep the balance between reasonableness and effectiveness" (ibid., p. 40). In general, it provides an analytic instrument to deal with the fact that arguers would normally try to move toward the best position in view of the argumentative circumstances by some clever and skillful planning (see ibid., pp. 40-41). Particularly, in order to give a precise characterization, three aspects of strategic maneuvering are distinguished, all of which are associated with distinct types of choices: (1) the choice made from the available "topical potential", i.e., "the repertoire of options for making an argumentative move that are at the arguer's disposal in a certain case and at a particular point in the discourse", (2) the choice of how to adapt the argumentative move to meet "audience demand", i.e., "the requirements pertinent to the audience that is to be reached", and (3) the exploitation of "presentational devices", which involves "a choice as to how the argumentative moves are to be presented in the way that is strategically best" (ibid., pp. 93-94).

Seeing from the perspective of strategic design, the use of a conductive argument could also be regarded as an effort intentionally made by the arguer in order to achieve both effective- 
ness and reasonableness at the same time. The reasons for the conclusion are adduced obviously for the sake of maintaining reasonableness, because otherwise the conclusion cannot be accepted as justified, and the act would never be recognized as arguing. Meanwhile, some counter-considerations are mentioned with the aim to achieve an optimal effectiveness, because when they are deliberately juxtaposed with reasons for the conclusion, it would trigger some mechanism to enhance the arguer's chances of persuading the audience. This similarity, then, opens a possibility for us to understand conductive arguments as a mode of strategic maneuvering, and to analyze and evaluate them using the theoretical tools pertinent to that notion. ${ }^{3}$

\section{Conductive argument as a mode of strategic maneuvering: Its analysis}

In extended Pragma-dialectical theory, every instance of strategic maneuvering will be categorized into one of the four classes, based on the stage in which it takes place: confrontational maneuvering, opening maneuvering, argumentational maneuvering, and concluding maneuvering. Each of these four classes will encompass "a variety of specific modes of strategic maneuvering whose make-up is instrumentally attuned to realizing the dialectical and rhetorical aims pertinent to the discussion stage the arguers are in" (van Eemeren 2010, p. 46). In accordance with this framework, conductive arguments would be regarded as a particular mode of argumentational maneuvering, for any use of a conductive argument will be reconstructed as part of the argumentation stage, more specifically, as a move in argumentation stage that might be "dialectically allowed, and serves the arguer's rhetorical interest with greatest effectiveness" (ibid., p. 43).

In presenting a conductive argument, besides giving reasons for the conclusion, the arguer chooses to provide some considerations against it, while at the same time maintaining the conclusion to be unqualified, i.e., leaving it without any modifi-

\footnotetext{
${ }^{3}$ Some readers might think that here I am inconsistent in taking a rhetorical perspective on conductive arguments while at the time proposing to understand them as a mode of strategic maneuvering, because the notion of strategic maneuvering involves a combination of both dialectical and rhetorical insights. To avoid this confusion, I would like to point out that the rhetorical perspective on conduction argued in this paper stresses the rhetorical role of counter-considerations, but it does not exclude the logical or dialectical function of reasons for the conclusion.
}

(C) Yun Xie. Informal Logic, Vol. 37, No. 1 (2017), pp. 2-22. 
cation. Therefore, the specific maneuver that has been strategically performed here is the purposive mentioning of some counter-considerations in such a way that just makes them appear to be trivial. And by doing so, the arguer intends to make her argument appear more solid, and improves its persuasiveness. Arguably, this consists of the most important feature that needs to be accounted for in analyzing a conductive argument. When adopting the theoretical tools pertaining to strategic maneuvering, making use of a conductive argument could be further analyzed into three aspects, all of which will be helpful in explaining its special mechanism in achieving an optimal persuasiveness.

First, any use of a conductive argument involves a choice carefully made from the topical potential at the arguer's disposal. When arguing conductively, the arguer not only chooses several positive considerations to construct her argument for the conclusion, but more importantly, she also selects prudently some of the available counter-considerations to be mentioned. The number of counter-considerations has to be limited, and their contents will always be restricted to points that count apparently and directly against the conclusion, rather than the positive reasons adduced in the argument. Moreover, the counterconsiderations to be mentioned also need to be meaningful, in such a way that only considerations that are (recognized as) worthy of taking into account, and could potentially or actually be known by the audience, will be considered for mentioning. Accordingly, when those deliberately selected negative points are offered along with the positive reasons, and after their value being recognized, it leaves to the audience an impression that the arguer really knows about the topic well, and has already thought about it in a thorough way. Meanwhile, the arguer herself will very likely be perceived as an honest, objective or open-minded person, because it appears as though she is willing to take into account both favorable and unfavorable considerations in order to present a more candid and less biased appraisal of the conclusion. These effects would in turn boost the arguer's credibility for the audience and thereby increase her chances of persuading them.

Second, any use of a conductive argument involves an intentional adaption to meet the audience demand. Generally, when there is a need to argue for some claim to someone, it just means that that particular person is possibly or actually having some doubts or objections to that claim. In other words, the addressee of the argument will normally be preconditioned with an initial skepticism, and in many cases, she might already have 
had in mind some concerns against the claim to be argued. However, as indicated above, the meaningful counterconsiderations to be presented are always some points whose existence and significance are already familiar to the audience. It is quite rare to see a conductive argument containing some counter-consideration that is not commonly known, or makes no sense in the eyes of the audience. Therefore, by mentioning those specific negative points in her argument, the arguer not only shows her respect for the audience's skeptical attitude and their opposing views, she also manifests explicitly her acknowledgement of their value and importance in thinking about the issue. This could easily be recognized as some concession made by the arguer to her audience, and helps to establish some communion between them. As a result, the arguer may have successfully reduced the audience's confrontational orientations, and enhanced the possibility of persuading them.

Third, any use of a conductive argument involves the exploitation of a special presentational device. There are indeed different possible ways to include a counter-consideration in an argument. It could be mentioned and discussed, for instance, by examining its truth, relevance, or justificatory power. More often than not, a counter-consideration is introduced for scrutiny or refutation. However, in a conductive argument, counterconsiderations are simply mentioned in a non-refutational way, with no attempt to discuss or to remove them. Specifically, they are juxtaposed straightforwardly with the supportive reasons in a particular comparative manner, by using an even-though type clause. As indicated, the use of this clause joins two propositions in a rhetorically unequal way with exactly opposite orientations, where the proposition in the clause has been downplayed in importance, while the other is particularly emphasized (Hansen 2011, p. 44). Presenting counter-considerations in such a delicate way would impose to the audience an assumption of some outweighing-relation between the reasons for the conclusion and the counter-considerations against it, and thereby leaves to them an impression that the arguer has had some good reason to believe the conclusion is certainly defensible against those counter-considerations. Then the audience would be oriented to recognize the counter-considerations as weaker, wrong or no longer viable, and to believe that their importance has already been eliminated somewhere else for some possible reasons, even though the arguer has provided nothing to actually account for these judgements. Consequently, the audience's own attitude towards the conclusion may be changed, and they might become more apt to accept it, especially when they don't really 
have a good grasp of the justificatory power in those counterconsiderations. ${ }^{4}$

\section{Conductive argument as a mode of strategic maneuvering: Its evaluation}

It is also feasible, and to some extent promising, to evaluate conductive arguments with the normative standards corresponding to strategic maneuvering. In the Pragma-dialectical framework, strategic maneuvering is performed by an arguer in order to achieve effectiveness through reasonableness, however, "the conditions that need to be fulfilled in order to ensure effectiveness do not necessarily always agree with the conditions that have to be met to guarantee reasonableness" (van Eemeren 2010, p. 41). In cases of strategic maneuvering where the arguer's pursuit of effectiveness overwhelms her commitment to reasonableness, they will "derail" into fallaciousness (ibid., p. 198), for every argumentative move will primarily be required to meet the dialectical norms of reasonableness. Therefore, "each mode of strategic maneuvering has in principle unreasonable, i.e., fallacious, counterparts" (van Eemeren, Garssen \& Meuffels 2012), and "all derailments of strategic maneuvering are fallacies in the sense that they violate one or more of the rules for critical discussion" (van Eemeren 2010, p. 198).

Accordingly, the evaluation of conductive argument would become much simpler and straightforward if it were taken to be a particular mode of strategic maneuvering: a conductive argument is good when its use as an argumentative move doesn't violate any rule of critical discussion, and it is bad when its use as an argumentative move violates at least one rule of critical discussion. In general, any use of a conductive argument consists of a twofold effort: offering some reasons for the conclusion to establish its acceptability, and mentioning some coun-

\footnotetext{
${ }^{4}$ Both Francisca Snoeck Henkemans and Eveline Feteris suggested to me that the use of an even-though type clause might also perform several other functions in different cases. For example, it could be used to refer to something, showing the speaker's awareness of it, or, to acknowledge something, either in its propositional content or in its justificatory power (cf. Snoeck Henkemans 1992, pp. 143-153). This distinction, obviously, could deepen our understanding of the use of concessive expressions in general, but I don't think it would make much difference for analyzing the persuasive effects of conductive argument in particular, because when arguing conductively counter-considerations are not just conceded (referred to or acknowledged), but more importantly, outweighed.
}

(C) Yun Xie. Informal Logic, Vol. 37, No. 1 (2017), pp. 2-22. 
ter-considerations to achieve an optimal effectiveness in persuading. Hence the uses of conductive argument could violate the rules of critical discussion in several different ways.

On the one hand, things could go wrong in an arguer's endeavor to adduce reasons for the conclusion. For example, she might bring into discussion some claim that is not granted by the other party, thus violating the starting-point rule. She could also afford some reason that is not relevant to the conclusion, thus violating the relevance rule. Moreover, she could possibly violate the validity rule by using an invalid form of reasoning, or violate the argument scheme rule by applying an argument scheme incorrectly.

On the other hand, there could also be possible violations of critical discussion rules in an arguer's endeavor to mention counter-considerations, and it is in these cases that we could detect the most common and significant fallacious counterparts of conductive argument. First and foremost, by presenting counterconsiderations in the particular comparative manner, the arguer will impose on the audience an assumption of some outweighing-relation. Therefore, the arguer's use of a conductive argument could violate the starting-point rule, if the outweighingrelation assumption to be imposed has not been granted by the addressee of the argument. For example, consider the following argument from a student, who is asking the teacher to save him from the final exam that he has failed in a terrible way:

Even though I didn't do well in the final exam, you should still consider letting me pass this course, because I really worked hard on this course for the whole semester, and have learned something in this course.

When arguing in this way, the student has obviously taken for granted that the efforts made in a course, and the fact that a student has acquired something from the course, could together outweigh a terrible failure in the final exam. However, it is easy to see that this conductive argument could hardly work, because very few teachers would take that assumption as acceptable. Hence it should be judged as a fallacious move violating the starting-point rule.

Secondly, the use of a conductive argument could violate the relevance rule, if the mentioned counter-considerations are 
indeed not relevant to the conclusion. ${ }^{5}$ The following example is taken from Govier's A Practical Study of Argument (2010, p. 367):

The American Revolution was not a typical revolution. For one thing, the people in revolt were mainly middle class or upper class-not peasants. For another, the object of attack was something far away-a government in England - not the close structure of the society in which the war occurred. Despite the fact that it is called a revolution, and despite its great importance for the history of the world, the American Revolution should not be thought of as a model for other revolution.

In this conductive argument, the arguer has just presumed some relevance between the fact that "the American Revolution has great importance for the history of the world" and the view that "the American Revolution should be regarded as a model for other revolutions". Therefore, she decided to mention the former as a counter-consideration against her conclusion. However, as Govier has explained, this counter-consideration is indeed not relevant, "because the importance of the events for world history has nothing to do with this issue of whether a revolution was typical or not" (p. 413). As a result, the use of this conductive argument violates the relevance rule, and should be judged as a fallacious move.

\section{Weighing some counter-considerations}

I hope I have demonstrated that a rhetorical perspective on conduction is possible, and the proposal to analyze and evaluate it as a mode of strategic maneuvering is viable. Here I would also like to introduce some counter-considerations into my argument,

${ }^{5}$ It could also be theoretically possible to think that the arguer herself has already believed all the counter-considerations to be mentioned are simply irrelevant. Then, the reason she is still willing to introduce them into the argument might be the intention to show her being knowledgeable or informed about the issue, or, to emphasize the absurdness of the counter-considerations by a comparison with the reasons for the conclusion. Nevertheless, this alternative view would render every use of conductive argument into a violation of the relevance rule, a consequence that seems to be too radical. Here I cannot scrutinize this view with a fuller discussion, but it would suffice to note that this interpretation of conduction is also rhetorical in nature, and it won't undermine the position argued in this paper.

(C) Yun Xie. Informal Logic, Vol. 37, No. 1 (2017), pp. 2-22. 
with an aim to further defend and clarify the position argued in this paper.

For the first, it might also be possible to understand mention of counter-considerations from a dialectical, rather than a rhetorical, perspective: the arguer's endeavor to include counterconsiderations could likewise be regarded as some effort to fulfill dialectical obligations, or to pursue the dialectical reasonableness. ${ }^{6}$ In this regard, the inclusion of counter-considerations might well be a way that the arguer has taken to deal with possible doubts, or anticipated objections. Then it would be too strong to take it as simply aiming for achieving rhetorical effectiveness.

In general, all arguments are made within a dialectical setting. The same is true for conductive arguments. The arguer's choice of counter-considerations is in many ways audienceoriented, and the counter-considerations to be mentioned are quite often known by the addressee. However, this observation only reveals that the counter-considerations presented in conductive arguments are in nature dialectical materials, but it cannot warrant the claim that the act of mentioning them is truly some effort aiming for dialectical reasonableness. And this is particularly the case when conductive arguments are concerned. As indicated, when arguing conductively, the arguer has intentionally presented counter-considerations in a non-refutational way, and in a special manner that makes them appear to be simply outweighed and trivialized. In this sense, counterconsiderations are first acknowledged, but then brushed aside directly without offering any reasons. This would hardly be taken as a dialectically acceptable way to deal with possible doubts or anticipated objections. Therefore, I am apt to suspect that the mention of counter-considerations in conductive arguments could fulfill any dialectical obligation, and to doubt the plausibility of treating it as some effort for pursuing dialectical reasonableness.

And for the same reasons, I am also reluctant to follow Blair's alternative proposal that is basically formulated from an epistemic point of view:

One good reason for including both the pros and the cons in our arguments is that doing so is epistemically responsible. On the assumption that we have an obligation to accurately and honestly convey the strength of our evidence or other grounds for our conclusions in our argu-

\footnotetext{
${ }^{6}$ I am very grateful to Bart Garssen for bringing this point into my attention.
} 
ments, mentioning the counter-considerations ... indicates fully the nature of the support we take that conclusion to have ... [and] indicates that the argument is weaker than it would be thought to be if only the pro considerations had been mentioned. (Blair 2016, p. 124, italics mine.)

Here Blair believes that the arguer's communicational intent for offering counter-considerations is to manifest her openness and sincerity to all the relevant evidence, and thereby to indicate the possible weakness of her argument. However, I think this view simplifies the matter by neglecting the point that those counterconsiderations were already taken by the arguer to be overridden, and were mentioned deliberately in a particular way that makes their importance downplayed, rather than truly acknowledged or conceded. Moreover, it also contradicts the fact that in each use of a conductive argument there is always an outweighing-relation between the pros and cons that had been imposed by the arguer, and recognized by the addressee. This outweighingrelation, obviously, would eliminate right away the possible negative effects made by those counter-considerations on the conclusion. Therefore, it is hard to say that the arguer's mentioning of counter-considerations, as in a conductive argument, is a way of being epistemically responsible to fully indicate the variety of relevant evidences and to qualify her argument to some degree.

Nevertheless, to some extent I do agree with Blair in saying that a conductive argument is weaker than it would be thought to be if only the reasons for the conclusion had been offered. But this claim also needs to be further qualified as "logically or epistemically weaker". Moreover, the weakness of conductive arguments does not lie in the explicit mention of some counter-considerations, they are weaker because of some kind of incompleteness: arguing conductively has arbitrarily presumed as acceptable a working outweighing-relation that has played too fundamental a role in justifying the conclusion, hence cannot be left assumed and unexamined. ${ }^{7}$ However, this weakness can

7 This incompleteness is particularly unacceptable for those who would like to take a logical perspective on conduction. When counter-considerations are regarded as relevant to the justification of the conclusion, i.e., as reasons or premises of the argument, a logical gap emerges and must be filled by an onbalance premise. Then the original argument has to be reconstructed and extended. To some extent, the rhetorical perspective on conduction argued in the paper has just challenged this interpretation by pointing out that this incompleteness could also be tolerable if it is indeed the arguer's intention to argue in that way.

(C) Yun Xie. Informal Logic, Vol. 37, No. 1 (2017), pp. 2-22. 
only be detected when the addressee of the argument seriously challenges that presumption and starts to examine its correctness. Otherwise, the presumption would become a powerful embellishment that just makes the argument rhetorically stronger.

The second counter-consideration I would like to address regards a possible implication of the rhetorical perspective on conduction that seems to be counterintuitive or unacceptable. To be more specific, if the mention of counter-considerations in conductive arguments is not truly an effort to enhance justificatory power, but an attempt to achieve better persuasive effect, then, the concept of conduction would lose its charming characteristic of capturing our way of reaching a conclusion by weighing and balancing between the reasons for and against it. However, I believe this anxiety might turn out to be illusory, because such a characterization of conductive argument itself could be questionable.

To better clarify this point, here I would like to rely on a distinction between thinking and arguing. Roughly speaking, weighing and balancing is a process of thinking in which we critically inquire into an issue, trying to consider both the pros and cons in order to reach a certain (reasonable) view. The use of a conductive argument, on the other hand, is an act of arguing by which we intend to persuade some other to accept a particular view that we have already reached and currently hold. Therefore, arguing conductively for a conclusion cannot be the same as weighing and balancing to reach that conclusion, but arguing conductively has to be preconditioned with a completed inquiry about the conclusion by weighing and balancing, for otherwise it is more likely a way of deception. However, if such an inquiry to reach the claim in the conclusion is ended, there will always be an outweighing-relation that is actually adduced, and needs to be justifiable (at least) to the thinker who has completed that inquiry. In this connection, a conductive argument, as is presented when put to use, is merely a short-circuited retrospective reconstruction of a finished process of weighing and balancing, without the inclusion of the outweighing-relation and its justification. Therefore, it is misleading to characterize conduction simply as a special structure in which both affirmative and negative points bearing on the conclusion are explicitly collected, weighed and balanced. Its real distinctiveness lies more in the fact that a conductive argument relies for its own legitimacy on a completed inquiry of weighing and balancing, and represents 
that inquiry intentionally with an abridged version that leaves its most significant part unexpressed. ${ }^{8}$

Hence the beauty of conductive argument, then, is not in its representation of the justification mechanism by weighing and balancing, but in the specific way that it is used to represent that mechanism. It is also due to this distinguishing feature that we can well explain why the use of conductive argument is dialectically allowable and rhetorically effective. A conductive argument leaves some elements that had played significant roles in justifying the conclusion presumed and unclarified. Accordingly, it is dialectically allowable only when those missing elements are permissible to be hidden in the context where the argument is used, that is, the outweighing-relation, as well as its justification, could be reasonably granted by the addressee of the argument. Moreover, a conductive argument is rhetorically effective, because it derives an enhanced persuasive strength from the use of a linguistic strategy that makes the conclusion appear to be the verdict of a completed critical inquiry, thus improving the appearances of both the argument and the arguer.

\section{Conclusion}

The concept of conductive argument captures a special way of arguing that is commonly recognized in argumentative practice, but has long been overlooked in our argumentation studies. It really is a challenging task to explain why we collected both positive and negative considerations into one structure, and how it works to establish a standpoint and to achieve persuasion. Other than searching for a logical or epistemological account, this paper offers a rhetorical perspective on conduction. It is contended that the inclusion of counter-considerations in a conductive argument is mainly for rhetorical concerns, particularly in order to better persuade the audience. Hence the use of conductive arguments becomes a special argumentative move that aims not only for justifying the conclusion, but also for optimizing its effectiveness.

This interpretation establishes a linkage between conductive arguments and strategic maneuvering, and opens a possibil-

\footnotetext{
${ }^{8}$ It is for this reason that I think most of the theoretical issues on conductive arguments urged by its proponents are actually questions about the thinking process of weighing and balancing, or questions about critical inquiry. Their legitimacy and significance are not bound to a recognition of conductive argument as a new logical type.
}

(C) Yun Xie. Informal Logic, Vol. 37, No. 1 (2017), pp. 2-22. 
ity to understand conductive argument as a particular mode of strategic maneuvering. It is demonstrated that the use of conductive arguments could be analyzed and evaluated in an adequate way by adopting the theoretical tools pertinent to strategic maneuvering developed in extended Pragma-dialectics. Hence the mechanism and structure of conduction need not be explained purely from a logical perspective.

Moreover, it is argued that a conductive argument presupposes a completed inquiry of weighing and balancing, but does not represent it faithfully. It represents that inquiry in a particular way in which some essential elements are left unexpressed on purpose, but a presentational device is used to improve its appearance and persuasive power. Accordingly, it is suggested that conductive arguments should not be characterized by a mechanism of weighing and balancing, and the appeal for treating them as a new logical type of argument might be misleading, if not problematic.

Acknowledgements: The basic ideas in this paper were presented at the First Sino-Dutch conference on Pragma-Dialectics and the 11th OSSA conference, I am very grateful to the audience and to my commentator in these occasions for their insightful questions and comments. I would also like to thank three Informal Logic referees and James Freeman for their very valuable feedback on a previous draft. The work in this paper is supported by the National Social Science Fund Projects (13CZX063), and the Chinese MOE Project of Key Research Institute of Humanities and Social Sciences at Universities (15JJD720014).

\section{References}

Adler, J. E. (2013). Are conductive arguments possible? Argumentation 27(3), 245-257.

Blair, J.A. (2016). A Defense of Conduction: A Reply to Adler, Argumentation 30 (2), 109-128.

Blair, J.A. (2013). Are conductive arguments really not possible? In: D. Mohammed and M. Lewiński (Eds.), Virtues of argumentation: Proceedings of the 10th international conference of the Ontario Society for the Study of Argumentation (pp. 1-13), Windsor, ON: OSSA. 
Blair, J.A. (2011). Conductive Reasoning/Arguments: A map of the issues. In J.A. Blair \& R.H. Johnson (Eds.), Conductive Arguments: An Overlooked Type of Defeasible Reasoning (pp. 1-9). London: College Publications.

Blair, J.A., \& R.H. Johnson (Eds.). (2011). Conductive arguments: An overlooked type of defeasible reasoning. London: College Publications.

van Eemeren, F.H. (2010). Strategic maneuvering in argumentative discourse: Extending the pragma-dialectical theory of argumentation. Amsterdam-Philadelphia: John Benjamins.

van Eemeren, F.H. \& Houtlosser, P. (2002). Strategic maneuvering: Maintaining a delicate balance. In F.H. van Eemeren \& P. Houtlosser (Eds.), Dialectic and rhetoric: The warp and woof of argumentation analysis (pp. 131-159). Dordrecht: Kluwer Academic.

van Eemeren, F. H., Garssen, B. \& Meuffels, B. (2012). Effectiveness through reasonableness. Preliminary steps to pragma-dialectical effectiveness research. Argumentation 26(1), 33-53.

Govier, T. (2011). Conductive arguments: Overview of the symposium. In J.A. Blair \& R.H. Johnson (Eds.), Conductive Arguments: An Overlooked Type of Defeasible Reasoning (pp. 262-276), London: College Publications.

Govier, T. (2010). A Practical Study of Argument, $7^{\text {th }}$ ed. Belmont CA: Wadsworth, Cengage Learning.

Govier, T. (1987). Problems in Argument Analysis and Evaluation. Dordrecht: Foris Publications.

Govier, T. (1979). Carl Wellman's Challenge and Response. The Informal Logic Newsletter 2(2), 10-15.

Hansen, H.V. (2011). Notes on balance-of-consideration arguments. In J.A. Blair \& R.H. Johnson (Eds.), Conductive Arguments: An Overlooked Type of Defeasible Reasoning (pp.31-51). London: College Publications.

Snoeck Henkemans, A. F. (1992). Analysing complex argumentation. Amsterdam: SicSat.

O'Keefe, D. (1999). How to handle opposing arguments in persuasive messages: a meta-analytic review of the effects of one-sided and two-sided messages. In: Michael Roloff (ed.). Communication Yearbook 22 (pp. 209-249), Sage Publications.

Possin, K. (2012). The Myth of Conductive Arguments, Inquiry: Critical Thinking across the disciplines. 27(3), 29-33.

Wellman, C. (1971). Challenge and Response: Justification in Ethics. Carbondale \& Edwardsville: Southern Illinois University Press. 
Wohlrapp, H. (2011). Conductive argument: a misleading model for the analysis of pro- and contra-argumentation. In J.A. Blair \& R.H. Johnson (Eds.), Conductive Arguments: An Overlooked Type of Defeasible Reasoning (pp. 210-223). London: College Publications.

Xie, Y. \& Xiong, M. (2013). Commentary on: J. Anthony Blair's "Are conductive arguments really not possible?" In: D. Mohammed and M. Lewiński (Eds.), Virtues of argumentation: Proceedings of the 10th international conference of the Ontario Society for the Study of Argumentation (pp. 1-6), Windsor, ON: OSSA. 